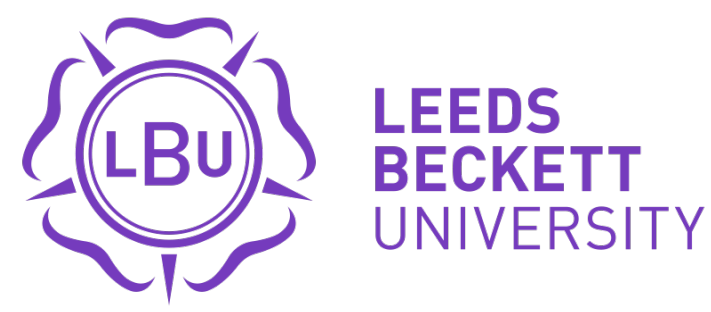

Citation:

Maun, R and Fabri, M and Trevorrow, P (2021) Adapting Participatory Design Activities for Autistic Adults: A Review. In: Design, User Experience, and Usability: Design for Diversity, Well-being, and Social Development. Springer International Publishing, pp. 300-314. ISBN 9783030782245 DOI: https://doi.org/10.1007/978-3-030-78224-5_21

Link to Leeds Beckett Repository record:

https://eprints.leedsbeckett.ac.uk/id/eprint/8174/

Document Version:

Book Section (Accepted Version)

This is a post-peer-review, pre-copyedit version of a chapter published in Design, User Experience, and Usability: Design for Diversity, Well-being, and Social Development. The final authenticated version is available online at: https://link.springer.com/chapter/10.1007\%2F978-3-030-78224-5_21

The aim of the Leeds Beckett Repository is to provide open access to our research, as required by funder policies and permitted by publishers and copyright law.

The Leeds Beckett repository holds a wide range of publications, each of which has been checked for copyright and the relevant embargo period has been applied by the Research Services team.

We operate on a standard take-down policy. If you are the author or publisher of an output and you would like it removed from the repository, please contact us and we will investigate on a case-by-case basis.

Each thesis in the repository has been cleared where necessary by the author for third party copyright. If you would like a thesis to be removed from the repository or believe there is an issue with copyright, please contact us on openaccess@leedsbeckett.ac.uk and we will investigate on a case-by-case basis. 


\title{
Adapting Participatory Design Activities for Autistic Adults: A Review
}

\author{
Rachael Maun ${ }^{1[0000-0003-4724-6828]}$, Marc Fabri ${ }^{1[0000-0003-0603-7704]}$ \\ and Pip Trevorrow ${ }^{1[0000-0002-0635-338 X]}$ \\ ${ }^{1}$ Leeds Beckett University, Leeds LS6 3QS, UK \\ r.maun@leedsbeckett.ac.uk, m.fabri@leedsbeckett.ac.uk, \\ p.trevorrow@leedsbeckett.ac.uk
}

\begin{abstract}
This paper presents a literature review investigating the suitability of participatory design when conducted with autistic adults. Six relevant papers were discovered, with key information extracted prior to analysis. A thematic analysis revealed six core themes of adaptations and considerations to be made when working with autistic adults: (1) appropriate approaches and methodology, (2) individual differences, (3) flexibility, (4) communication, (5) environment and sensory issues and (6) challenge assumptions. Overall, it was found that participatory design is a suitable method for use with autistic adults, providing careful adjustments are made to some or all of the design activities to ensure their accessibility and effectiveness. It is important that researchers and practitioners have sufficient autism understanding to make these adjustments, and that they invest time to get to know the autistic people involved in their study.
\end{abstract}

Keywords: Autism, Participatory Design, Human-centered Design, Co-design, User-centered Design

\section{Introduction}

Participatory design (PD) has been a focal point of many scholarly articles on the effective conception or re-design of technology. This is partly attributed to the success of design firms such as IDEO and Continuum who specialize in the innovation of new products, services and experiences derived from user-centered design methods (Continuum, 2019; IDEO, 2019). UCD refers to design approaches which consider end users as sources of innovation, with their insights heard, behaviors observed, and needs met (Lowdermilk, 2013). This then informs the iterative development of new products, services and experiences (Bordin \& Angeli, 2017; Dell'Era \& Landoni, 2014; Rogers et al., 2019).

In traditional UCD, users are not active participants in the research process, rather they are used as a testing and evaluation service for designers. Participatory design builds on the premise of UCD by involving users more actively in the design process, from conception of an idea through to prototype testing at the end of the design process (Roberston \& Simonsen, 2012). Users are empowered to make decisions and contribute 
as partners throughout the design process, offering contributions and expert knowledge. (Anthony et al., 2012; Constantin et al., 2019; Robertson \& Simonsen, 2012).

In this paper, we investigate how autistic people can be involved in the participatory design of technology for this user group. This considers characteristics, preferences and strengths as well as the suitability of established PD methods and potentially the conception of new methods.

\subsection{Terminology}

For the purpose of this paper, the terms "autistic adult" and "adult on the autism spectrum" will be adopted. This is based on recent research by Kenny et al. (2016), showing that most autistic adults prefer 'identity first' language as opposed to 'person first' terminology i.e. 'adult with autism'. This has also been mirrored by autistic people who took part in the Autism\&Uni project (Fabri et al., 2016).

\section{$2 \quad$ Autistic characteristics}

Autism spectrum condition (ASC) is a lifelong pervasive neurodevelopmental condition, characterized by impairments in social communication. Other characteristics of autism include repetitive and restrictive behaviors, which can impact on both the individual and their family's lives (APA, 2013). Autism is also considered a spectrum condition, with some individuals showing mild symptoms while others display more severe symptoms (Anderson et al., 2014; Dillenburger et al., 2015). It is estimated that around 1 in 100 people in the UK are autistic (Baird et al., 2006), and autism can occur with or without other intellectual disabilities with $69 \%$ of autistic people having no intellectual disabilities, and around $46 \%$ with average or advanced intellect (Anderson et al., 2018).

For this paper, we focus on autistic adults without intellectual difficulties as this is a group that has traditionally been under-researched, with participatory design research in autism often involving children with learning difficulties and/or communication impairments (Aresti-Bartolome \& Garcia-Zapirain, 2014). The work is done in the context of a research project that aims to create technology to support and inform autistic university students.

\section{$3 \quad$ Participatory Design with autistic people}

The use of PD with autistic people has grown over recent years, with autistic children between the ages of 8 and 12 being the most often researched group (Börjesson et al., 2015). The use of PD with autistic children has spawned a variety of new technologies, with outputs ranging from learning aids (Guldberg et al., 2017), social communication tools (Abdullah \& Brereton, 2017; Harrold et al., 2014), mental health aids (McGowan et al., 2017; Simm et al., 2016), to language tools (Plaisted Grant et al., 2019).

Several researchers, including Benton et al., (2011) and Frauenberger et al., (2012), have acknowledged that standard PD methods may not be suitable for autistic children 
for a variety of reasons, and techniques may need to be modified to meet individual needs and abilities (Francis, Mellor, et al., 2009). The primary reason that traditional PD methods may not be suitable is due to the key need for collaboration between design team members, something which autistic children may struggle with due to a lack in communication and social skills (Benton et al., 2011). Generating ideas can also be challenging for autistic children (Benton et al., 2014).

Additionally, there is a heightened fear of failure in autistic children, which can serve as a barrier to creativity and participation (Francis, Balbo, et al., 2009). When comparing the use of PD with typically developing children, adults are involved in the process more intensively, with adults including; users, proxies, experts and facilitators (Börjesson et al., 2015).

\subsection{PD Methods for working with children}

Responding to the concern about involving autistic children, a series of new participatory design methods have been researched and developed. These include IDEAS (Benton et al., 2011), an Interface Design Experience for the Autistic Spectrum, which amends existing participatory design methodologies with a quiet environment to reduce distractions, an initial explanation of the proposed session, a visual timeline, demonstrations of existing software and the integration of hobbies and interests of the target group as identified in previous questionnaires (ibid).

Others identified a need to build a relationship with the children prior to embarking on the design process, with some researchers spending months building rapport with the students (Börjesson et al., 2015). The ECHOES project also used a specifically designed participatory design approach with both typically developing children and those with special needs. Their research concluded that the use of non-digital formats was found to be imperative to overcoming barriers to creativity, especially in autistic children (Frauenberger et al., 2011).

\subsection{PD methods for working with adults}

In contrast, research into the use of participatory design with autistic adults is underrepresented, with very few papers investigating its use. Examples of research include; the development of serious games for autistic teenagers (Bossavit \& Parsons, 2016b, 2016a; Mohd et al., 2019), the development of self-tracking tools for tracking their everyday lives (S.-I. I. Kim et al., 2019; Ryu et al., 2017), the development of an online peer support network (MacLeod, 2010) and the development of an online toolkit to aid with the transition into higher education (Fabri et al., 2016).

Crucially, there is limited literature surrounding suitable preparations and adaptations when conducting participatory design with autistic adults. The assumption has been made that these will be similar to those adaptations applied when involving autistic children (Nicolaidis et al., 2019). However, this assumption needs to be challenged. Previous work has indicated that visual preferences and interaction preferences may well be different with this group (Fabri et al 2016). 
A gap in knowledge surrounding autistic adults has been uncovered in recent years. Large cohorts of children were diagnosed as autistic in the 1990's and early 2000s, with research and interventions for autistic children and adolescences forming the majority of research on autistic people (Piven et al., 2011; Warner et al., 2019). Those autistic children have now reached adulthood and would benefit from increased research on issues that affect them as autistic adults, yet this has not been a focal point of research thus far (ibid).

Research has also shown that autistic people, regardless of cognitive abilities, still benefit from support and accommodations to succeed in gaining independence or progress with their education (Glennon, 2001), yet there is still limited information on how to meet the specific needs of this group (Vanbergeijk et al., 2008).

This leads to the current paper, where the focus is on evaluating the suitability of participatory design with autistic adults with no intellectual disabilities, something that thus far appears to have been neglected.

\section{$4 \quad$ Method}

Literature was reviewed from a number of online scientific databases including; ACM, ERIC, MEDLINE, PsychINFO, Academic Search Complete, NAS and Scopus. The search strategy included terms (and synonyms) for; autism, participatory design, codesign, design thinking, co-creation, human-centered design, human-centered computing, computing and technology. Given the advent of Design Thinking as a generalizable approach to participatory design in the mid-2000s (Plattner et al 2011), peer reviewed papers from the past 15 years were included. Upon completion of the literature search, 17 papers were identified as relevant.

Papers using PD with adolescents or teens were removed as research has shown that the preferences of children and young people differ from those of adults (Chevalier et al., 2017; Fabri \& Andrews, 2016), leaving a total of 7 papers focusing specifically on the use of PD with autistic adults. Upon reading the papers, a further paper was removed (Kim et al., 2020) as there was no reference to adaptations made to the PD approach to better meet the needs of autistic adults. Table 1 summarizes the papers included in this review.

Table 1. Summary of Papers included

\begin{tabular}{|l|l|}
\hline Author & Summary of Paper \\
\hline Aslam et al (2019) & $\begin{array}{l}\text { PD was used to empower autistic adults to design their own } \\
\text { social robot. The process incorporated building blocks to } \\
\text { guide autistic participants through an iterative co-design } \\
\text { process and incorporated scaffolding to bridge imaginative } \\
\text { and communication-related gaps }\end{array}$ \\
\hline Cascio et al (2020) & $\begin{array}{l}\text { PD was used to design a bio-music smartphone application } \\
\text { with a wearable sensor for measuring physiological signals }\end{array}$ \\
\hline
\end{tabular}




\begin{tabular}{|l|l|}
\hline & $\begin{array}{l}\text { to translate to auditory output. Strategies developed from re- } \\
\text { searchers and the autistic community were used to create a } \\
\text { space which was more accessible for autistic participants. }\end{array}$ \\
\hline Fabri et al (2016) & $\begin{array}{l}\text { PD was used to develop an online toolkit to help with the } \\
\text { transition into higher education. A 5-step design thinking } \\
\text { approach was applied, with various stakeholders involved at } \\
\text { various points. Participants in PD activities included; autis- } \\
\text { tic students, parents and friends of autistic people. }\end{array}$ \\
\hline $\begin{array}{l}\text { Fletcher-Watson et } \\
\text { al (2019) }\end{array}$ & $\begin{array}{l}\text { UK based seminars were organized in collaboration with au- } \\
\text { tistic and non-autistic people. These seminars focused on } \\
\text { considerations to be made when conducting PD research } \\
\text { with autistic adults. 5 core themes were identified; respect, } \\
\text { authenticity, assumptions, infrastructure and empathy. }\end{array}$ \\
\hline MacLeod (2010) & $\begin{array}{l}\text { PD was used to develop an online 'AS Portal' for peer-to- } \\
\text { peer support for autistic higher education students. The pro- } \\
\text { ject was student-led, with the design and development } \\
\text { steered by the students involved. }\end{array}$ \\
\hline $\begin{array}{l}\text { Nicolaidis et al } \\
\text { (2019) }\end{array}$ & $\begin{array}{l}\text { PD guidelines were created, based on research using PD } \\
\text { methods with autistic adults between 2006-2018. These } \\
\text { guidelines were developed in collaboration with autistic } \\
\text { adults and academics. 7 key themes were identified; trans- } \\
\text { parency, clearly defined roles, clear processes for communi- } \\
\text { cation and power sharing, building and maintaining trust, } \\
\text { collaboratively disseminate findings, actively encourage } \\
\text { community capacitation and fairly compensate participants } \\
\text { for their work. }\end{array}$ \\
\hline
\end{tabular}

From each of the remaining 6 papers, key information was extracted prior to analysis, following the approach by Börjesson et al. (2015):

- name and description of the developed technology,

- details about the autistic participants,

- details about any other participants, e.g. facilitators, designers, coders, mentors

- the phases of inclusion in the design process,

- the methods and techniques used with the target group in each phase,

- any autism-specific adaptations made to methods, techniques or phases

- any adaptations recommended on completion of the study

\section{$5 \quad$ Results}

Six core themes emerged from the extracted information, highlighting important considerations when planning and conducting PD with autistic adults. Table 2 highlights the themes and sub-themes that were extracted from the papers, following the approach by Börjesson et al. (2015). The themes will be described in more detail in the following sections. 
Table 2. Themes and Subthemes Identified

\begin{tabular}{|l|l|}
\hline Theme & Subthemes \\
\hline $\begin{array}{l}\text { Appropriate Approaches } \\
\text { and Methodology }\end{array}$ & Methods \\
& Defining stakeholders involved \\
& PD stages \\
Planning
\end{tabular}

\subsection{Appropriate Approaches and Methodology}

Across the papers reviewed, a number of different PD approaches were identified including; a 'design after design approach' (Cascio et al., 2020), a five-step design thinking method (Fabri et al., 2016), a four-phase iterative design method (B. Kim et al., 2020), an entirely student-led approach (MacLeod, 2010), a community-based participatory research method (Nicolaidis et al., 2019), and a bottom-up participatory approach (Aslam et al., 2019). Though these approaches all have different names and descriptions, they all follow traditional design thinking methodologies commonly used in PD. Below we will explore the adjustments made to these established methodologies.

Aslam et al., (2019) stated that successfully collaborating with autistic participants in PD is fundamentally about managing, facilitating and guiding interplay between freedom and structure. It was also highlighted that encouraging autistic participants to open 
up about their emotions, continuously co-constructing the groups understanding of the technology and its' functioning, embedding researchers into the research space a few weeks prior to commencement, choosing appropriate approaches to meet partnership goals, considering the abilities and preferences of the participants and considering who should be included on the team were all vital to the success of PD (Cascio et al., 2020; MacLeod, 2010).

The inclusion of participants in all phases of the design was also considered important. Cascio et al., (2020) facilitated this by allowing autistic participants to organize the workshops themselves. Nicolaidis et al., (2019) involved participants in the dissemination of findings and MacLeod, (2010) gave participants roles of responsibility within the group and offered participants a draft of the final report to make comments should they wish. This full involvement of participants throughout all stages of the PD process is not often seen in research and shows that fully involving autistic participants in the design process can be achieved. This was also noted in reflections from Fabri et al., (2016) who felt that users could have been involved in earlier stages of the design, creating an uninterrupted continuum of user involvement.

A number of reflections were also made on the PD approaches used. Aslam et al. (2019) realized that simply providing participants with the 'building blocks' was not sufficient in fostering creativity. Instead, a narrative had to be added to the design sessions to encourage technological familiarity, imaginative skills and collaborative and social skills. Participants needed further encouragement to make decisions, reconsider their ideas, mix ideas, reflect on their ideas and diverge and reframe iteratively. Fabri et al. (2016) found that combining the 'prototype' and 'test' stages worked well as it did not require careful structuring but still produced useful feedback. Other methods such as focus group interviews and 'day in the life of...' diaries and data collection needed further consideration, as some participants were able to verbally recount relevant experiences but were unable to type them into an online form, despite wishing to do so.

\subsection{Individual Differences}

Four of the papers highlight the need to address individual differences. Some autistic participants may need structure and guidance within a PD workshop as they may struggle with imaginative and abstract thinking. It can help to give these participants examples and explicit demonstrations. Other autistic participants may find it easier to be 'naturally' creative (Aslam et al., 2019).

Individual differences may also include adjustments to the materials for accessibility, for example Nicolaidis et al., (2019) had to adjust materials to be suitable for a blind participant in their workshops, they integrated braille materials and offered 3D raised graphs so that they could be included in the workshops. By acknowledging and understanding participants' individual differences, ideas of what adjustments may be needed can be highlighted and offering these adjustments can help them feel a part of the workshops, and in turn allow them to contribute effectively. There may also be individual differences that are considered positives, for example Fabri et al., (2016) found participants who appeared to cope better than others despite starting from the same situation. 
These were labelled as 'positive deviants' which can provide valuable insights into how these individuals managed to succeed, and positive strategies can be shared with the group.

\subsection{Flexibility}

While addressing individual differences, it is also important to be flexible in an approach to meet the needs of those with individual differences or preferences. Cascio et al. (2020), for example, highlights the importance of allowing participants to make contributions to the workshop in a way of their choosing. This may include stereotypical methods such as short videos, interviews, questionnaires, discussions, audio recordings, but may also include more abstract methods such as; poetry, art work, different types of recording and even abstract dance (in the case of their workshops focusing on biomusic).

This focus on flexibility was also highlighted as important by MacLeod, (2010) who suggests that there should be options for participants to choose from when engaging in interviews, this may include; face-to-face interviews, telephone interviews, real-time email interviews and the use of instant messenger chat, this can maximize the inclusion of autistic participants with different strengths and needs. Maintaining flexibility at all times, paying close attention to individualized needs and making accommodations can help with participation. Aslam et al., (2019) mirrored the sentiment of having a flexible approach, by allowing participants the freedom to discover their own pathway, letting their creativity unfold with a balance between creative freedom and structure.

\subsection{Communication}

When considering good communication within a PD group, Cascio et al. (2020) \& Nicolaidis et al. (2019) offer some initial recommendations:

- Being transparent

- Defining roles within the group from the outset

- Communicating and offering channels for communication (e.g. offering participants the opportunity to ask questions or share concerns, either via email, on the phone or face-to-face)

- Share power

- Build and maintaining trust

- Sharing findings and building a community

- Communicating how participants may be fairly compensated, should this be the case

Many of these are arguably general "good practice" and would be part of a research study's ethical considerations. This makes them particularly relevant to design practitioners conducting activities outside of an institutional ethics framework.FletcherWatson et al., (2019) mirrors these recommendations by highlighting the importance of openly communicating about the research focus and methods from the offset to help 
contextualize the work and educate participants about the research process, the dialogue should also be open, not constrained by specific research questions.

Creating a shared language has also been highlighted as important, this involves introducing academic jargon selectively, allowing a shared understanding of terminology to be built over the course of the workshops and allowing the participants to create their own shared language (Cascio et al., 2020; Nicolaidis et al., 2019).

It is also pertinent to highlight the importance of respectful communication between group members. This consists of asking for consideration from each of the members. An example of considerate communication between group members is to ask a team member to stop banging on the table as other members may find this distracting or overwhelming (Cascio et al., 2020; Fletcher-Watson et al., 2019). Respectful communication can also consist of giving all project members an opportunity to communicate, in a judgement free environment. Participants have commented on how it feels good to be listened to and been given the space and time to share experiences (Fabri et al., 2016). Differences should also be recognized, and an acceptance that there may not always be agreement should be established, this can generate a mutual respect between autistic and non-autistic members of the group (Fletcher-Watson et al., 2019).

Open discussion is also important, though this needs to be achieved by both the participants and the facilitators. This can allow for the development of a common shared experience facilitators (Cascio et al., 2020). Fletcher-Watson et al., (2019) builds on this by also stating that facilitators should also be prepared to learn from workshop participants and be prepared to make changes in response to feedback. Power imbalances should also be addressed although it is not always possible to avoid this.

It is also important to maintain communication channels throughout the entire project, this means allowing participants to ask questions even when the workshops are completed (Fletcher-Watson et al., 2019). MacLeod, (2010) suggests offering participants a draft of the report upon completion of the research and asking for comments or feedback on the report, this ensures participants are involved until the end of the research project.

\subsection{Environment and Sensory Issues}

Considering the environment in which the workshops are being facilitated is another important aspect of designing with autistic participants. Cascio et al., (2020) highlights the importance of autism friendly spaces, a space in which autistic participants feel safe and can access, where autistic participants can be themselves, accomplish their goals and navigate more easily. It may also be worth considering meeting autistic participants in a place of their choosing (Fletcher-Watson et al., 2019).

Having used a number of different sites for their workshops, Cascio et al., (2020) were able to see the impact the environment can have on autistic participants. Most workshops took place within Spectrum Productions, a specifically co-designed space for autistic people. Aside from an initial complaint about the facilitator's cologne, not liking being touched, not liking loud noises and not liking a specific guitar riff within the researched bio-music, the use of Spectrum Productions proved to be a successful 
space to conduct PD. When the research was moved to a university classroom, problems arose, one participant left the room and was unable to return due to the strong perfumes worn by students, to crowdedness of the room and closed windows.

Aslam et al., (2019) highlighted an interesting use of the physical space within workshops. The left-hand side of the room was a 'problem space' where participants started blueprinting ideas. Once participants were happy with their blueprints, they moved to the right-hand side of the room to actively build their technology. These spaces were used iteratively, with continuous and rapid movement between the spaces, where the problems and solutions could co-evolve, allowing for the problem to be reframed and solutions to diverge into a variety of novel combinations.

Other aspects to consider include, allowing participants to stim during the workshops (Cascio et al., 2020) and the need for a quiet space where participants can retreat if they feel they need to (Fletcher-Watson et al., 2019).

\subsection{Challenge Assumptions}

Challenging assumptions was also considered an important aspect of PD, especially when working with autistic participants. Fabri et al., (2016) highlighted the importance of challenging stereotypes surrounding autism spectrum condition. For example, there is an assumption that autistic people think visually, which was not found to be true. Instead, autistic participants preferred well-structured text over infographics or videos and only preferred visual information when it depicted real people or places, or when it specifically added to the text information being presented.

Examples of what was considered an appropriate use of visual information included the use of photographs of landmarks for directions, photographs of people they would be meeting and photos of the buildings and rooms in which the workshops were being carried out. Another example of an assumption that was challenged was that autistic people lack creativity and imaginative thinking. Participants were able to contribute to the design process creatively and imaginatively providing the environment and situation was comfortable for them. Fletcher-Watson et al., (2019) mirrored the need to challenge assumptions, as there are diverse patterns of autism, and also highlighted the importance of allowing autistic participants to flag these assumptions should they arise within the workshops.

Nicolaidis et al., (2019) also highlighted that it cannot be assumed that survey instruments that have been validated with the general population will work with autistic participants. Surveys and interview guides may need to be adapted to be more accessible to autistic participants.

\subsection{Conclusions}

Based on this review, we argue that participatory design can be a suitable design methodology for autistic adults. Despite the challenges outlined, participatory design is considered vital when aiming to design tools that meets end-users' needs and are usable. Excluding members of society from the design process because current design practice 
is not a good fit for this group is clearly unethical. There is an obligation on the designer's part to adapt the methods employed, so that the desired outcome can be achieved. Or in other words, the obligation is to make design practice more inclusive. Any autism characteristics which may pose as a barrier to involvement in participatory design activities need to be fully understood and the activities adapted. Researchers and practitioners will have to ensure they have the time and are willing to put in the effort to make these adjustments.

Key issues of choosing appropriate methodologies and approaches can be easily overcome by considering the ability and preferences of participants. Varying degrees of participation can also be successful, providing the correct adjustments are made. Entering into PD with autistic adults blindly may result in some initial teething issues but providing workshop facilitators take the time to listen to the wants, needs and preferences of participants, and take the time to address any issues or feedback, any challenges should be easily rectified.

Challenges surrounding individual differences can also be easily overcome with a selection of adjustments, some encouragement to promote abstract thinking and acknowledgement of these individual differences rather than ignorance towards them.

Flexibility is key in PD, particularly when collaborating with autistic adults. An inclusive approach where participants are given options for how to contribute their experiences and preferences is needed. For example, data does not have to be collected in stereotypical ways, e.g. questionnaires and interviews, and participants should be encouraged to contribute in a way which they feel is appropriate and safe for them. It is important to consider the overall aims and objectives of any study. Some studies may benefit from online only questionnaires, where others may require methods such as interviews, focus groups etc. and these can be adapted to meet individual needs e.g. phone interviews, email interviews, large focus groups, smaller focus groups and oneto-one design sessions.

Another important aspect is communication: communicating effectively from the outset, with defined roles, rules and communication channels, can ground the design project effectively. Being clear with participants about what is expected of them, what can be expected of the facilitators and what is expected from the group can negate early disagreements. This includes giving participants the opportunity to communicate their preferences and strengths prior to any activities. Allowing participants to develop their own language can generate a feeling of belonging, and all communication within the group should be respectful and open.

Considering the environment is something that must not be overlooked when working with autistic individuals. Sensory issues are prevalent in autistic individuals (Kojovic et al., 2019) and ensuring there are no strong smells, loud noises or overcrowded areas can help autistic people feel safe in an environment. As highlighted by Cascio et al., (2020), autism-friendly spaces should be considered as the chosen environment for PD workshops with autistic adults, but if this is not possible, selecting a quiet area, away from crowds, is recommended.

Finally, researchers should challenge assumptions of autism when working with autistic adults. Despite previous literature stating that autistic people prefer visual information, Fabri et al., (2016) found this was not the case when working with a group of 
autistic university students. With autism being such a diverse condition, with each case being unique (Chapman, 2020), it could create a barrier to participation if making assumptions on the autistic population as a whole. By the same token, however, assumptions should not be made that the use of standard measures used with neurotypical groups will also apply to groups of autistic adults.

It is important that anyone wanting to conduct participatory design activities with autistic adults requires an understanding of autism that goes beyond a general level of awareness. This includes the understanding that each autistic person must be considered individually when planning design activities, so that adjustments can be made on an individual basis.

\section{References}

Abdullah, M. H. L., \& Brereton, M. (2017). Mycalendar: Supporting Children on the Autism Spectrum to Learn Language and Appropriate Behaviour. Proceedings of the 29th Australian Conference on Computer-Human Interaction, 201-209. https://doi.org/10.1145/3152771.3152793

Anderson, A., Carter, M., \& Stephenson, J. (2018). Perspectives of University Students with Autism Spectrum Disorder. Journal of Autism and Developmental Disorders, 48(3), 651665. https://doi.org/10.1007/s10803-017-3257-3

Anderson, K. A., Shattuck, P. T., Cooper, B. P., Roux, A. M., \& Wagner, M. (2014). Prevalence and correlates of postsecondary residential status among young adults with an autism spectrum disorder. Autism (London) VO - 18, 5, 562.

Anthony, L., Prasad, S., Hurst, A., \& Kuber, R. (2012). A Participatory Design Workshop on Accessible Apps and Games with Students with Learning Differences. Proceedings of the 14th International ACM SIGACCESS Conference on Computers and Accessibility, 253254. https://doi.org/10.1145/2384916.2384979

APA. (2013). Diagnostic and Statistical Manual of Mental Disorders: DSM-IV-TR (5th ed). American Psychaitric Association.

Aresti-Bartolome, N., \& Garcia-Zapirain, B. (2014). Technologies as support tools for persons with autistic spectrum disorder: a systematic review. International Journal of Environmental Research and Public Health, 11(8), 7767-7802.

Aslam, S., van Dijk, J., \& Dertien, E. (2019). CoCoCo: Co-Designing a Co-design toolkit for Co-bots to empower autistic adults. In 4th RTD Conference: Design United (Issue 4, pp. 1-16). https://doi.org/10.6084/m9.figshare.7855904.v2

Baird, G., Simonoff, E., Pickles, A., Chandler, S., Loucas, T., Meldrum, D., \& Charman, T. (2006). Prevalence of disorders of the autism spectrum in a population cohort of children in South Thames: the Special Needs and Autism Project (SNAP). The Lancet, 368(9531), $210-215$.

Benton, L., Johnson, H., Brosnan, M., Ashwin, E., \& Grawemeyer, B. (2011). IDEAS: An Interface Design Experience for the Autistic Spectrum. CHI '11 Extended Abstracts on Human Factors in Computing Systems, 1759-1764. https://doi.org/10.1145/1979742.1979841

Benton, L., Vasalou, A., Khaled, R., Johnson, H., \& Gooch, D. (2014). Diversity for Design: A 
Framework for Involving Neurodiverse Children in the Technology Design Process. Proceedings of the SIGCHI Conference on Human Factors in Computing Systems, 37473756. https://doi.org/10.1145/2556288.2557244

Bordin, S., \& Angeli, A. De. (2017). Inoculating an Agile Company with User-Centred Design: An Empirical Study. In Agile Processes in Software Engineering and Extreme Programming : 18th International Conference, XP 2017, Cologne, Germany, May 22-26, 2017, Proceedings (p. 235). Springer International Publishing. https://doi.org/10.1007/978-3-319-57633-6_15

Börjesson, P., Barendregt, W., Eriksson, E., \& Torgersson, O. (2015). Designing Technology for and with Developmentally Diverse Children: A Systematic Literature Review. Proceedings of the 14th International Conference on Interaction Design and Children, 79-88. https://doi.org/10.1145/2771839.2771848

Bossavit, B., \& Parsons, S. (2016a). Designing an Educational Game for and with Teenagers with High Functioning Autism. Proceedings of the 14th Participatory Design Conference: Full Papers - Volume 1, 11-20. https://doi.org/10.1145/2940299.2940313

Bossavit, B., \& Parsons, S. (2016b). "This is How I Want to Learn": High Functioning Autistic Teens Co-Designing a Serious Game. Proceedings of the 2016 CHI Conference on Human Factors in Computing Systems, 1294-1299. https://doi.org/10.1145/2858036.2858322

Cascio, M., Grond, F., Motta Ochoa, R., Tembeck, T., Veen, D., \& Blain-Moraes, S. (2020). Working Together: Ethnographic Observations on Participatory Design Involving Adults with Autism. Human Organization, 79, 1-12. https://doi.org/10.17730/0018-7259.79.1.1

Chapman, R. (2020). The reality of autism: On the metaphysics of disorder and diversity. $\begin{array}{lll}\text { Philosophical Psychology, 33(6), } & \text { 799-819. }\end{array}$ https://doi.org/10.1080/09515089.2020.1751103

Chevalier, P., Martin, J.-C., Isableu, B., Bazile, C., \& Tapus, A. (2017). Impact of sensory preferences of individuals with autism on the recognition of emotions expressed by two robots, an avatar, and a human. Autonomous Robots, 41(3), 613-635.

Constantin, A., Korte, J., Fails, J. A., Alexandru, C. A., Dragomir, M., Pain, H., Good, J., Garzotto, F., Eriksson, E., \& Waller, A. (2019). Expecting the Unexpected in Participatory Design. Extended Abstracts of the 2019 CHI Conference on Human Factors in Computing Systems, SIG07:1--SIG07:4. https://doi.org/10.1145/3290607.3311758

Continuum. (2019). The Future. Made Real. ${ }^{T M}$. Online. https://www.continuuminnovation.com/en/

Dell'Era, C., \& Landoni, P. (2014). Living Lab: A Methodology between User-Centred Design and Participatory Design. Creativity \& Innovation Management, 23(2), 137-154. http://10.0.4.87/caim.12061

Dillenburger, K., Jordan, J.-A., McKerr, L., \& Keenan, M. (2015). The Millennium child with autism: Early childhood trajectories for health, education and economic wellbeing. Developmental Neurorehabilitation, $\quad$ 18(1), 37-46. https://doi.org/10.3109/17518423.2014.964378

Fabri, M., \& Andrews, P. C. S. (2016). Human-centered design with Autistic university students: Interface, interaction and information preferences. Lecture Notes in Computer Science (Including Subseries Lecture Notes in Artificial Intelligence and Lecture Notes in Bioinformatics), 9747, 157-166. https://doi.org/10.1007/978-3-319-40355-7_15

Fabri, M., Andrews, P. C. S. S., \& Pukki, H. K. (2016). Using design thinking to engage autistic 
students in participatory design of an online toolkit to help with transition into higher education. Journal of Assistive Technologies, 10(2), 102-114. https://doi.org/10.1108/JAT-02-2016-0008

Fletcher-Watson, S., Adams, J., Brook, K., Charman, T., Crane, L., Cusack, J., Leekam, S., Milton, D., Parr, J. R., \& Pellicano, E. (2019). Making the future together: Shaping autism research through meaningful participation. Autism, 23(4), 943-953.

Francis, P., Balbo, S., \& Firth, L. (2009). Towards co-design with users who have autism spectrum disorders. Universal Access in the Information Society, 8(3), 123-135. https://doi.org/10.1007/s10209-008-0143-y

Francis, P., Mellor, D., \& Firth, L. (2009). Techniques and recommendations for the inclusion of users with autism in the design of assistive technologies. Assistive Technology, 21(2), 5768.

Frauenberger, C., Good, J., Alcorn, A., \& Pain, H. (2012). Supporting the Design Contributions of Children with Autism Spectrum Conditions. Proceedings of the 11th International Conference on Interaction Design and Children, 134-143. https://doi.org/10.1145/2307096.2307112

Frauenberger, C., Good, J., \& Keay-Bright, W. (2011). Designing technology for children with special needs: bridging perspectives through participatory design. CoDesign, 7(1), 1-28. $\mathrm{http} / /$ ezproxy.leedsbeckett.ac.uk/login?url=http://search.ebscohost.com/login.aspx?direc $\mathrm{t}=$ true $\& \mathrm{db}=\mathrm{a} 9 \mathrm{~h} \& \mathrm{AN}=61215473 \&$ site $=$ ehost-live \&scope $=$ site

Glennon, T. J. (2001). The stress of the university experience for students with Asperger syndrome. Work, 17(3), 183-190.

Guldberg, K., Parsons, S., Porayska-Pomsta, K., \& Keay-Bright, W. (2017). Challenging the Knowledge-Transfer Orthodoxy: Knowledge Co-construction in Technology-Enhanced Learning for Children with Autism. British Educational Research Journal, 43(2), 394 413. http://dx.doi.org/10.1002/berj.3275

Harrold, N., Tan, C. T., Rosser, D., \& Leong, T. W. (2014). CopyMe: An Emotional Development Game for Children. CHI '14 Extended Abstracts on Human Factors in Computing Systems, 503-506. https://doi.org/10.1145/2559206.2574785

IDEO. (2019). IDEO | ideo.com. Online. https://www.ideo.com/eu

Kenny, L., Hattersley, C., Molins, B., Buckley, C., Povey, C., \& Pellicano, E. (2016). Which terms should be used to describe autism? Perspectives from the UK autism community. Autism, 20(4), 442-462.

Kim, B., Lee, D., Min, A., Paik, S., Frey, G., Bellini, S., Han, K., \& Shih, P. C. (2020). PuzzleWalk: A theory-driven iterative design inquiry of a mobile game for promoting physical activity in adults with autism spectrum disorder. PLOS ONE, 15(9), 1-24. http://10.0.5.91/journal.pone.0237966

Kim, S.-I. I., Jo, E., Ryu, M., Cha, I., Kim, Y.-H. H., Yoo, H., \& Hong, H. (2019). Toward Becoming a Better Self: Understanding Self-Tracking Experiences of Adolescents with Autism Spectrum Disorder Using Custom Trackers. Proceedings of the 13th EAI International Conference on Pervasive Computing Technologies for Healthcare, 169178. https://doi.org/10.1145/3329189.3329209

Kojovic, N., Ben Hadid, L., Franchini, M., \& Schaer, M. (2019). Sensory processing issues and their association with social difficulties in children with autism spectrum disorders. Journal of Clinical Medicine, 8(10), 1508. 
Lowdermilk, T. (2013). User-centered design. [electronic resource] : a developer's guide to building user-friendly applications. O'Reilly. http://ezproxy.leedsbeckett.ac.uk/login?url=http://search.ebscohost.com/login.aspx?direc $\mathrm{t}=$ true $\& \mathrm{db}=$ cat $00621 \mathrm{a} \& \mathrm{AN}=$ leeds.518914\&site $=$ ehost-live\&scope $=$ site

MacLeod, A. (2010). 'Welcome to my first rant!' Report on a participatory pilot project to develop the 'AS portal', an online peer support network for higher education students on the autism spectrum. Journal of Assistive Technologies, 4(1), 14-24. https://doi.org/10.5042/jat.2010.0041

McGowan, J., Leplâtre, G., \& McGregor, I. (2017). CymaSense: A Novel Audio-Visual Therapeutic Tool for People on the Autism Spectrum. Proceedings of the 19th International ACM SIGACCESS Conference on Computers and Accessibility, 62-71. https://doi.org/10.1145/3132525.3132539

Mohd, C. K. N. C. K., Shahbodin, F., Jano, Z., \& Azni, A. H. (2019). Visual Perception Games for Autistic Learners: Design \& Development. Proceedings of the 2019 Asia Pacific Information Technology Conference, 5-11. https://doi.org/10.1145/3314527.3314533

Nicolaidis, C., Raymaker, D., Kapp, S. K., Baggs, A., Ashkenazy, E., McDonald, K., Weiner, M., Maslak, J., Hunter, M., \& Joyce, A. (2019). The AASPIRE practice-based guidelines for the inclusion of autistic adults in research as co-researchers and study participants. Autism, 23(8), 2007-2019.

Piven, J., Rabins, P., \& Group, A. A. W. (2011). Autism spectrum disorders in older adults: Toward defining a research agenda. Journal of the American Geriatrics Society, 59(11), 2151-2155.

Plaisted Grant, K., Fairclough, M. S., Friend, S. E., Malone, A. E., Varga-Elmiyeh, B., Weisblatt, E. J., Dias, C., Langensiepen, C. S., Cook, B., Dhariwal, M., Rybicki, A., Karanth, P., Belmonte, M. K., Dias, C., Plaisted Grant, K., Dhariwal, M., Fairclough, M. S., Friend, S. E., Malone, A. E., ... Belmonte, M. K. (2019). A Tablet Computer-Assisted Motor and Language Skills Training Program to Promote Communication Development in Children with Autism: Development and Pilot Study. International Journal of Human-Computer Interaction, 35(8), 643-665. http://ezproxy.leedsbeckett.ac.uk/login?url=http://search.ebscohost.com/login.aspx?direc $\mathrm{t}=$ true $\& \mathrm{db}=\mathrm{a} 9 \mathrm{~h} \& \mathrm{AN}=135587645 \&$ site $=$ ehost-live \&scope $=$ site

Roberston, T., \& Simonsen, J. (2012). Participatory Design: an introduction. In Routledge international handbook of participatory design (pp. 21-38). Routledge.

Robertson, T., \& Simonsen, J. (2012). Challenges and opportunities in contemporary participatory design. Design Issues, 28(3), 3-9.

Rogers, Y., Sharp, H., \& Preece, J. (2019). Interaction design. [electronic resource] : beyond human-computer interaction. (Fifth edit). Wiley. https:/go.openathens.net/redirector/leedsmet.ac.uk?url=http\%3A\%2F\%2Fsearch.ebscoh ost.com\%2Flogin.aspx\%3Fdirect\%3Dtrue \%26db\%3Dcat00621a\%26AN\%3Dleeds. 7762 57\%26site\%3Deds-live\%26scope\%3Dsite\%26authtype\%3Dathens

Ryu, M., Jo, E., \& Kim, S.-I. (2017). COSMA: Cooperative Self-Management Tool for Adolescents with Autism. Proceedings of the 19th International ACM SIGACCESS Conference on Computers and Accessibility, 409-410. https://doi.org/10.1145/3132525.3134825

Simm, W., Ferrario, M. A., Gradinar, A., Tavares Smith, M., Forshaw, S., Smith, I., \& Whittle, 
J. (2016). Anxiety and Autism: Towards Personalized Digital Health. Proceedings of the 2016 CHI Conference on Human Factors in Computing Systems, 1270-1281. https://doi.org/10.1145/2858036.2858259

Vanbergeijk, E., Kiln, A., \& Volkmar, F. (2008). Supporting More Able Students on the Autism Spectrum: College and Beyond. Journal of Autism and Developmental Disorders VO 38 , 7 ,

https://go.openathens.net/redirector/leedsmet.ac.uk?url=\%7BUrlEncode(http://search.ebs cohost.com/login.aspx?direct=true \&db=edscal\&AN=edscal.20569005\&site=edslive\&scope $=$ site $) \% 7 \mathrm{D} \% 26$ authtype $\% 3$ Dathens

Warner, G., Parr, J. R., \& Cusack, J. (2019). Workshop report: Establishing priority research areas to improve the physical health and well-being of autistic adults and older people. Autism in Adulthood, 1(1), 20-26. 